$$
\begin{aligned}
& 11-59 \\
& 0050=5
\end{aligned}
$$

NASA Technical Memorandum 110296

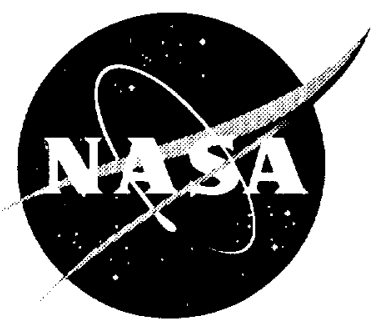

\title{
Development of Metallic Thermal Protection Systems for the Reusable Launch Vehicle
}

Max L. Blosser

Langley Research Center, Hampton, Virginia

October 1996

National Aeronautics and

Space Administration

Langley Research Center

Hampton, Virginia 23681-0001 



\title{
DEVELOPMENT OF METALLIC THERMAL PROTECTION SYSTEMS FOR THE REUSABLE LAUNCH VEHICLE
}

\author{
Max L. Blosser \\ NASA - Langley Research Center \\ Mail Stop 396 \\ Hampton, VA 23681-0001
}

(757) 864-5192

\begin{abstract}
A reusable Thermal Protection System (TPS) that is not only lightweight, but durable, operable and cost effective is one of the technologies required by the Reusable Launch Vehicle (RLV) to achieve the goal of drastically reducing the cost of delivering payload to orbit. Metallic TPS is one of the systems being developed to meet this challenge. Current efforts involve improving the superalloy honeycomb TPS concept, which consists of a foilgage metallic box encapsulating a low density fibrous insulation, and evaluating it for RLV requirements. The superalloy honeycomb TPS concept is mechanically attached to the vehicle structure. Improvements include more efficient internal insulation, a simpler, lighter weight configuration, and a quick-release fastener system for easier installation and removal. Evaluation includes thermal and structural analysis, fabrication and testing of both coupons and TPS panels under conditions simulating RLV environments. Coupons of metallic honeycomb sandwich, representative of the outer TPS surface, were subjected to low speed impact, hypervelocity impact, and rain erosion testing as well as subsequent arcjet exposure. Arrays of TPS panels have been subjected to radiant heating in a thermal/vacuum facility, aerodynamic heating in an arcjet facility and acoustic loading.
\end{abstract}

\section{INTRODUCTION}

The goal for the Reusable Launch Vehicle is to reduce the cost of delivering payloads to low earth orbit by an order of magnitude. To help achieve this goal, the thermal protection system for the RLV must be durable and operable, as well as low weight. Currently, more than 17,000 work hours (Green 1996) are expended to refurbish the TPS on the Space Shuttle after each flight. A goal of the RLV design is to reduce that refurbishment time so that the vehicle can fly again within a few days. Metallic TPS have several attractive features that offer the potential to help reach the RLV goals. The inherent ductility of metallic materials offer the potential of a more robust TPS outer surface. The geometric parameters in the metallic TPS offer the opportunity to modify the design to accommodate different conditions. For example, in the metallic TPS design, mass can easily be traded for improved durability by thickening the outer facesheet. Because prepackaged metallic TPS panels are inherently waterproof, they can be designed to support all weather operation by making the outer surface thick enough to resist required levels of rain erosion. Mechanical attachments can allow TPS panels to be quickly and easily removed for refurbishment, replacement or inspection of the underlying vehicle structure. MetallicTPS is therefore being developed for application to the RLV.

The three competing Phase 1 RLV concepts (Cook 1996) are shown in figure 1. Each of the three RLV concepts varied widely in both configuration and proposed TPS concepts. The TPS proposed for the wing-body vehicle (shown on the left of figure 1), by Rockwell International, was ceramic blankets over the acreage areas of the vehicle with rigid ceramic insulation tiles on the leading edges. McDonnell Douglas Aerospace (MDA) looked at two 
possible TPS configurations for the vertical landing vehicle (shown in the center of figure 1). The preferred configuration was a combination of advanced ceramic matrix composite heat shields and metallic panels for the acreage areas of the vehicle, with refractory composite nosecap and fin leading edges. The fallback configuration used advanced rigid ceramic tiles, and advanced flexible blanket for acreage areas with a refractory composite nosecap and rigid ceramic tile fin leading edges. The lifting body RLV (on the right of figure 1), proposed by Lockheed Martin, has an aeroshell comprised of metallic honeycomb TPS panels which covers the acreage areas of the vehicle. The nose cap and fin leading edges are made from carbon/carbon material. This concept was chosen for the $\mathrm{X}-33$ advanced technology demonstrator.

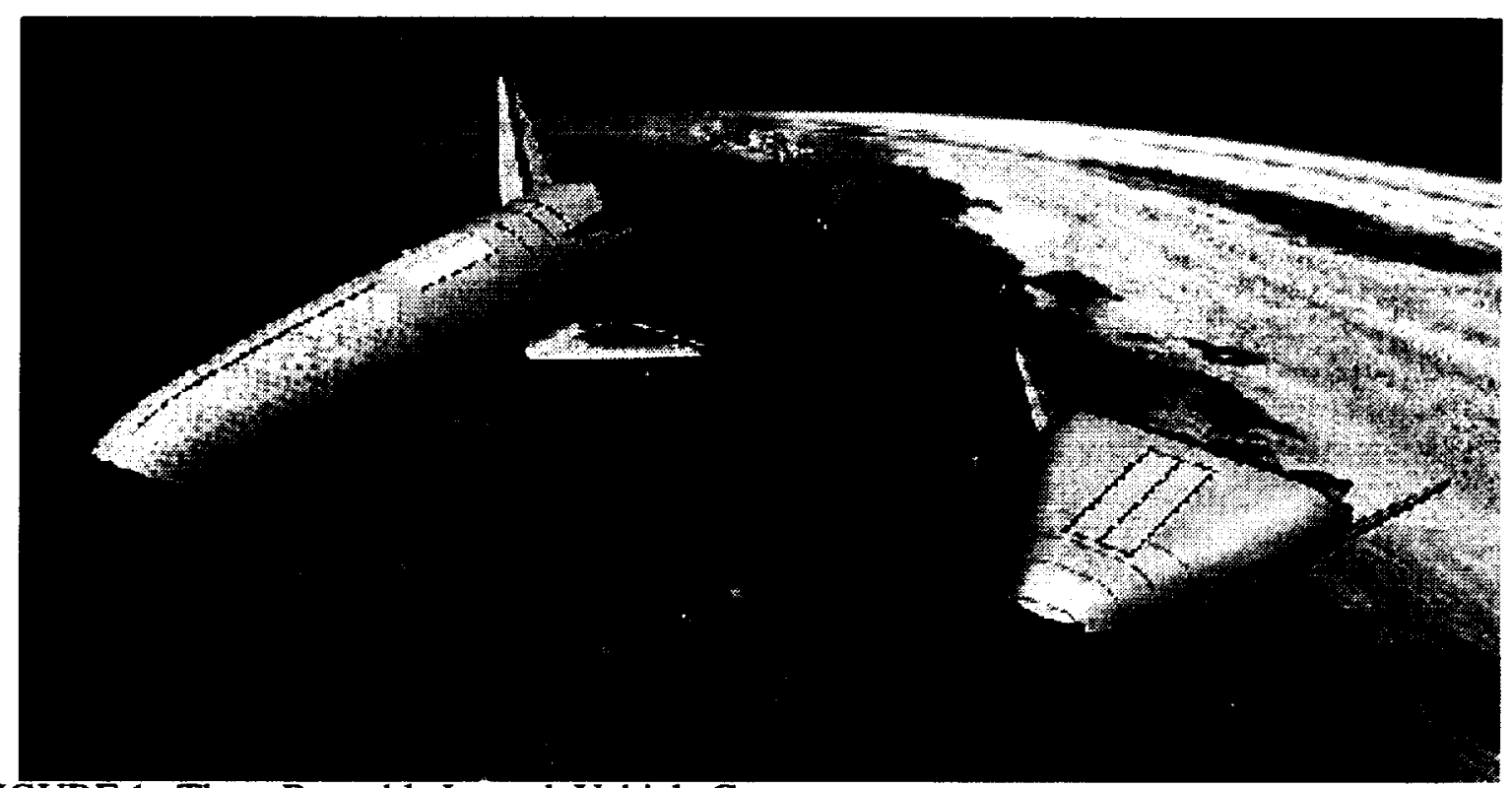

FIGURE 1. Three Reusable Launch Vehicle Concepts.

A technology development effort was undertaken in the first phase of the RLV program to mature some of the key technologies (Cook 1996), including TPS. NASA Langley Research Center and McDonnell Aerospace Corporation entered into a cooperative agreement to develop metallic and refractory composite thermal protection systems. Under this cooperative agreement, NASA LaRC has focused on the metallic TPS and MDA has focused on refractory composite TPS. Most of the metallic TPS development presented in this paper was generated under this cooperative agreement.

Much of the pioneering development of metallic TPS was led by NASA LaRC. Concepts progressed from early stand-off heat shields (Bohon 1977) to multiwall concepts (Jackson 1980, Shideler 1982, and Blair 1984) to prepackaged superalloy honeycomb sandwich panels (Blair 1985, Anderson 1989, and Gorton 1993). The detailed design and fabrication of the multiwall and prepackaged superalloy honeycomb TPS concepts were performed by Rohr Industries. Current efforts involve evaluating and improving the prepackaged superalloy honeycomb panel concepts.

The metallic TPS (David 1996), proposed for the Lockheed/Martin Venture Star X-33 vehicle and designed and fabricated by Rohr Industries, uses similar materials, thicknesses and fabrication techniques as the prepackaged superalloy honeycomb panels, but with some significant differences. The X-33 stand off metallic TPS (figure 2) uses the same foilgage, high temperature metallic honeycomb sandwich to form the outer surface as the prepackaged superalloy honeycomb panels. The outer honeycomb surface is supported at 
4 points by an underlying latticework to form an aeroshell that supports aerodynamic pressure loads. Fibrous insulation, beneath the outer honeycomb sandwich panel, is encapsulated by foil attached to the perimeter of the panel. Seals between panels on the outer surface are intended to maintain the aerodynamic pressure across the outer, hot honeycomb sandwich. In contrast, the prepackaged superalloy honeycomb TPS is vented so that there is little pressure difference across the outer honeycomb sandwich when it is hot. Because of the similar honeycomb sandwich construction of the outer surface and the common need for internal fibrous insulation, much of the technology development described in this paper is directly applicable to both the X-33 and the prepackaged superalloy honeycomb TPS concepts.

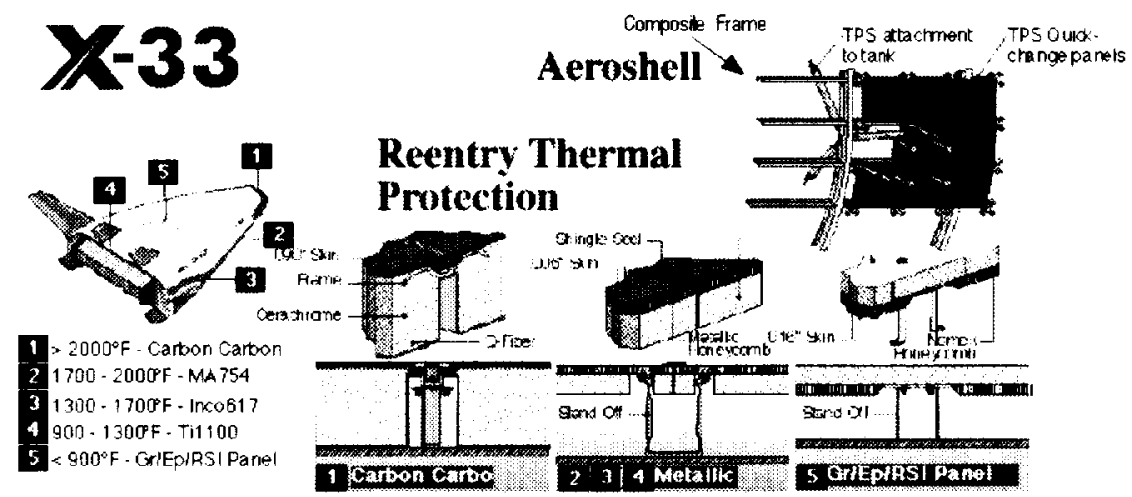

FIGURE 2. Thermal Protection System Proposed by Rohr Industries for X-33.

In this paper the design, analysis, fabrication and evaluation of an incrementally improved, prepackaged superalloy honeycomb TPS concept are described. Analytical tools and specialized testing facilities were developed to characterize more efficient internal insulations. Coupons of metallic honeycomb sandwich, representative of the outer TPS surface, were subjected to low speed impact, hypervelocity impact, and rain erosion testing as well as subsequent arcjet exposure. Arrays of TPS panels have been subjected to radiant heating in a thermal/vacuumfacility, aerodynamic heating in an arcjet facility and acoustic loading. A next generation metallic TPS design is identified which includes more efficient internal insulation, a simpler and lighter weight configuration, higher temperature materials and a quick-release fastener system for easier installation and removal. At the present time, some of the testing and evaluation has not yet been completed. This paper presents the status and an overview of some of the recent work on metallic TPS development.

\section{SUPERALLOY HONEYCOMB TPS PANELS}

A prepackaged superalloy honeycomb TPS concept was incrementally improved from a previous design and evaluated for RLV requirements. The superalloy honeycomb TPS concept, illustrated in figure 3 , consists of a foil-gage metallic box encapsulating a fibrous insulation.

The outer surface of the metallic box is comprised of a honeycomb sandwich with 0.005 in.-thick facesheets and a 0.0015 inch-thick, $3 / 16$ inch cell honeycomb core. The 0.003 inch-thick side walls are beaded to help alleviate thermal stresses and to resist buckling when carrying compressive loads. Both the outer honeycomb sandwich and the sides are made from Inconel 617, a nickel-based superalloy which enables the TPS to operate at a maximum temperature between $1800^{\circ} \mathrm{F}$ and $1900^{\circ} \mathrm{F}$-- with limited temperature excursions up to $2000^{\circ} \mathrm{F}$. On two adjacent edges of the panel, the outer facesheet and a flange from 
the beaded side extend approximately 0.3 inches to form a gap cover. This gap cover is designed to cover the gap with an adjacent, downstream panel to inhibit hot gas flow in the panel-to-panel gaps. For the 1-foot-square panels, a gap just over 0.2 inches is required to accommodate thermal expansion of the outer surface of the panel. Structural deformations may also play a role in determining the required panel-to-panel gap. A corresponding underhanging lip on the opposite two edges of the panel serve to close off the bottom of the panel-to-panel gap to contain any hot gas flowing in the gap.

The inner surface of the metallic box is made of a titanium alloy, $\mathrm{Ti} 6 \mathrm{Al}-4 \mathrm{~V}$. In the previous design, the lower surface consisted of titanium honeycomb sandwich, with 0.006 inch-thick facesheets and a 0.0015 inch-thick, $3 / 16$ inch cell honeycomb core. Away from the edges of the panel, the facesheets of the sandwich were chem-milled down to 0.003 inch thick. In the current concept the lower chem-milled facesheet and the associated honeycomb core were removed to reduce mass, leaving a 0.003 inch-thick foil on the interior of the lower surface to encapsulate the insulation framed by a section of titanium honeycomb sandwich which stabilizes the lower edges of the sides. A hole, covered by 400 mesh screen to keep out liquid water, is provided in the lower surface of the panel to vent the interior of the panel to the ambient pressure and thus limit the pressure difference supported by the metallic box.

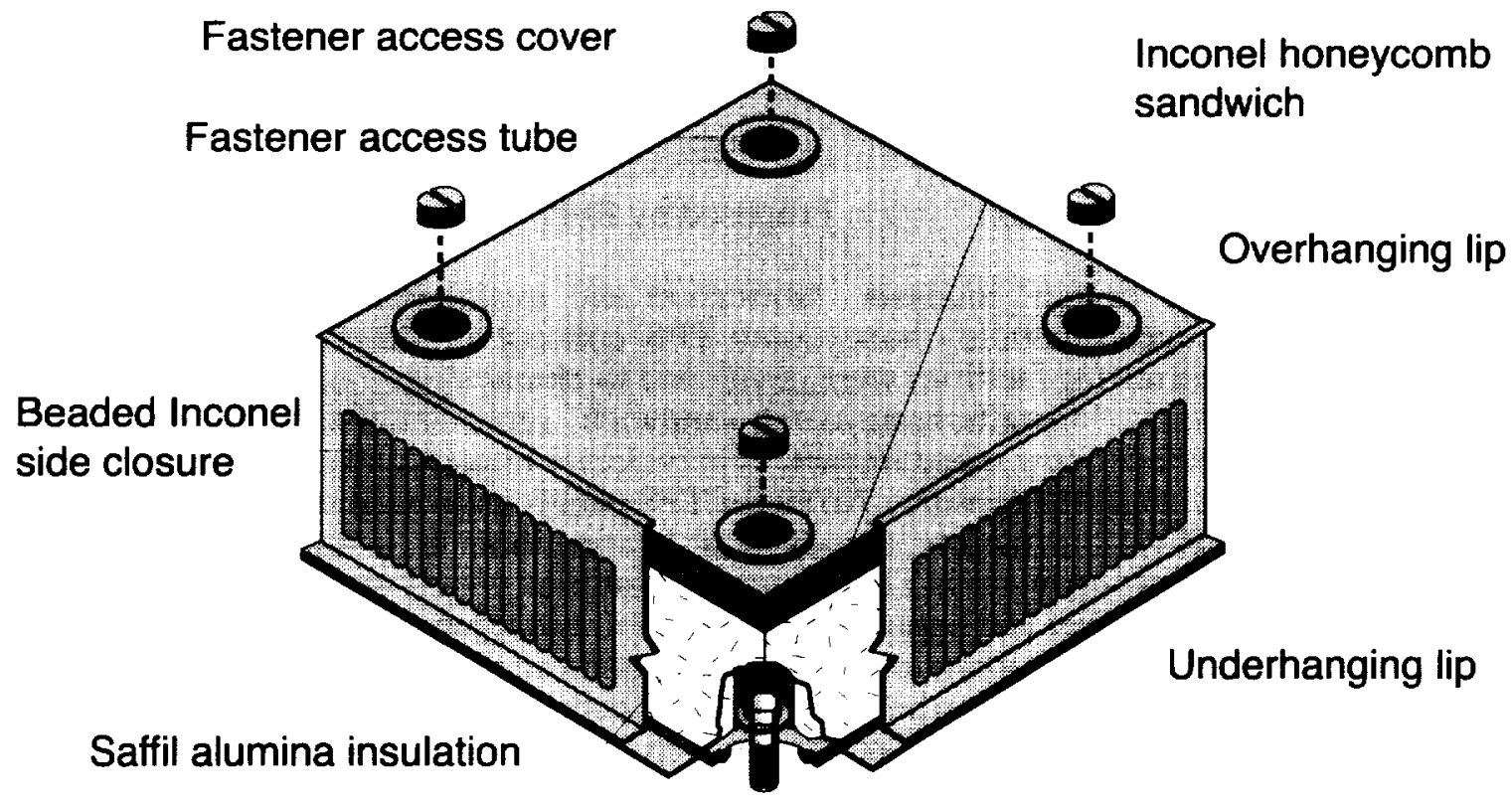

Titanium honeycomb

Titanium foil

Mechanical fastener

FIGURE 3. Prepackaged Superalloy Honeycomb TPS Panel.

The superalloy honeycomb TPS is designed to be mechanically attached to the vehicle structure. Fastener access tubes provide access from the outer surface of the TPS panel to holes in the inner surface of the panel which are smaller than the diameter of the access tube. The fastener presses against the bottom of the fastener access tube to hold the panel against the structure. A tool can be inserted into the fastener access tube to tighten or loosen the fastener. Threaded fastener access covers are provided to close off the fastener access tubes during operation. The fastener access tubes are filled with fibrous insulation to reduce heat transfer. A one-inch-thick strip of nomex felt, 0.19 inch-thick is centered 
beneath all panel-to-panel gaps. The nomex felt is coated with RTV adhesive to prevent flow beneath the panels. The mechanical fasteners are tightened to compress the nomex felt to approximately half its original thickness. The precompressed Nomex felt not only prevents hot gas flow beneath panels, it also helps damp out vibrations from vibratory and acoustic loading as well as providing a pretension on the fasteners that helps prevent them from loosening.

The primary function of inhibiting heat flow into the structure is performed by the internal insulation. Because the metal box maintains the structural integrity of the TPS, efficient insulation, which is not durable, may be used inside the box. The combination of $6 \mathrm{lb} / \mathrm{ft}^{3}$ Cerrachrome and $3.5 \mathrm{lb} / \mathrm{ft}^{3} \mathrm{Q}$-felt quartz fibrous insulation used in the previous TPS design (Blair 1985, Anderson 1989, and Gorton 1993) was replaced by a lighter 3.0 $\mathrm{lb} / \mathrm{ft}^{3}$ saffil alumina fibrous insulation in the current design. Other insulations are being considered as means of further reducing the mass of the system. Improved insulations include coated saffil alumina fibers for better reflection of radiation and internal multiscreen insulation, IMI (Veneri 1989 and Muhlratzer 1990).

\section{ANALYSIS}

Several analytical models were constructed to predict the thermal and structural behavior of superalloy honeycomb TPS. Detailed three-dimensional finite element and finite difference models were developed for the TPS panels. One-dimensional finite element heat transfer models were developed to predict complex thermal performance of fibrous and multilayer insulations as a function of temperature and pressure. A one dimensional TPS sizing code has been developed and enhanced to predict the thickness and mass of a TPS required for a particular location on a vehicle.

\section{Thermal}

One of the uncertainties associated with predicting the thermal performance of superalloy honeycomb is modeling the performance of the internal insulation. Heat transport mechanisms involve a complex interaction between radiation and conduction of the fibers and pressure dependent conductivity of air. Many of the candidate fibrous insulations are not well characterized for the temperatures and pressures encountered in the TPS environment (Gorton 1993). Also, analysis tools were not available to design the internal multiscreen insulation, which is being considered for enhanced TPS designs. Therefore one dimensional finite element codes were developed to analyze the thermal performance of both IMI and fibrous insulations. A three-dimensional finite difference model has been developed to predict the performance of superalloy honeycomb TPS panels. By using two planes of symmetry, a quarter panel model is used to represent an entire TPS panel. Honeycomb face sheets and core are modeled for the inner and outer honeycomb sandwich layers. Conductances of the metallic sides and fastener access tubes, as well as the mechanical fasteners were modeled. An effective thermal conductivity that varied as a function of temperature was used to represent the thermal performance of the internal insulation. A strip of nomex felt was modeled around the perimeter of the panel between the panel and the substructure. A uniform transient heat flux was applied to the outer surface of the model and the outer surface was allowed to reradiate heat as a function of its emissivity. The inner surface of the substructure was assumed to be adiabatic. Typical calculated temperature histories are shown in figure 4 through the center of a TPS panel. For this particular trajectory and configuration, the outer surface temperature peaks between $1800^{\circ} \mathrm{F}$ and $1900^{\circ} \mathrm{F}$ and the substructure temperature peaks at about $350^{\circ} \mathrm{F}$. 


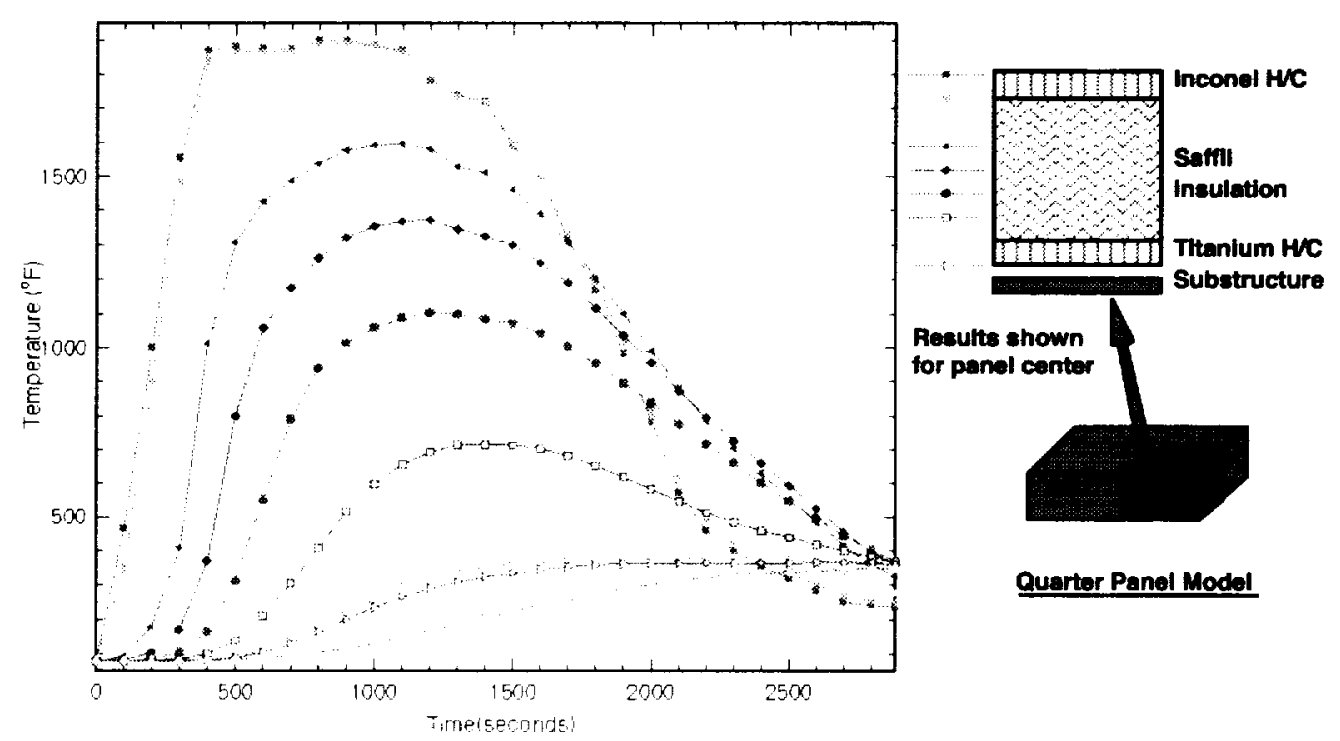

FIGURE 4. Typical Results of 3-Dimensional Finite Difference Thermal Model.

\section{Structural}

A three-dimensional structural finite element model was developed using the Engineering Analysis Language, EAL (Whetstone 1985), program for the superalloy honeycomb TPS panel to calculate the stresses and displacements under design loading. Using symmetry boundary conditions, only a quarter of the panel was modeled. The metallic box and underlying nomex felt were modeled, but the internal insulation was neglected in the structural model. The honeycomb sandwich was modeled using twodimensional element for the facesheets and three-dimensional elements with the appropriate orthotropic stiffness properties for the honeycomb core. The beaded sides of the panel were modeled using two-dimensional elements with orthotropic stiffness properties to simulate the directional stiffness of the beads.

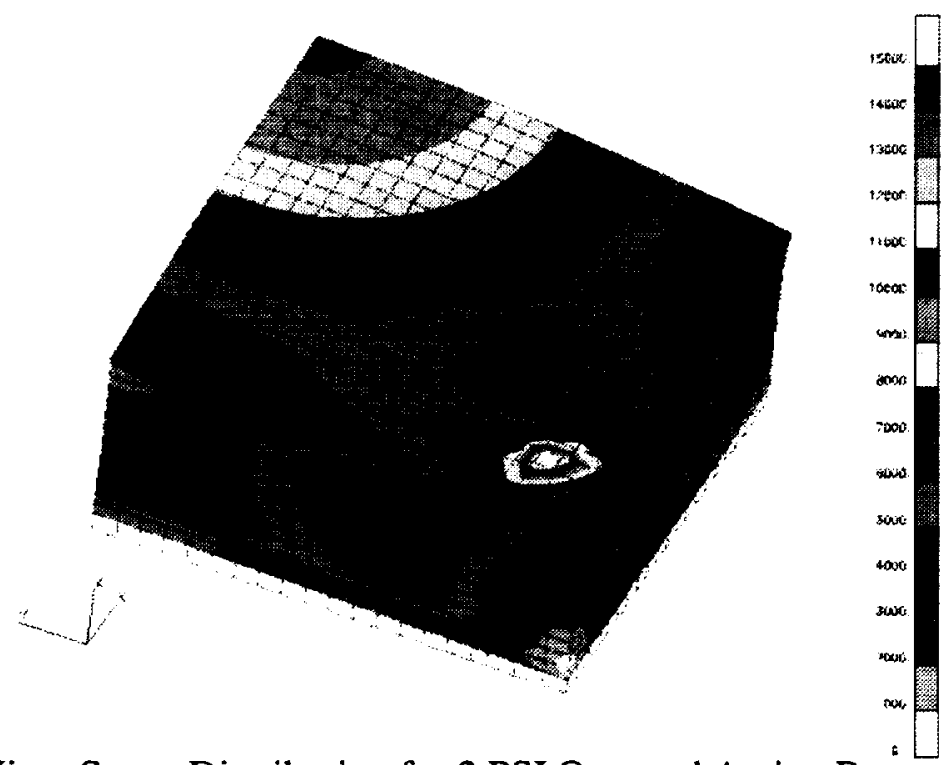

FIGURE 5. Von Mises Stress Distribution for 2 PSI Outward Acting Pressure on Outer Surface (psi). 
Two different static load cases were considered: an outward-acting pressure and a maximum thermal gradient. The interior of the superalloy honeycomb panel is vented to the local surface pressure so that, for most of the ascent and entry, the panel will see little or no pressure difference across the outer honeycomb sandwich. Near transonic speeds there is a possibility that rapidly moving shock waves may sweep over some portions of a vehicle generating transient pressure pulses over the outer surface of the TPS panels. A pressure loading of 2 psi was chosen (Blair 1985, Anderson 1989, and Gorton 1993) somewhat arbitrarily to represent this load case. The von Mises stress distribution is shown in figure 5 for a 2 psi loading acting outwardly on the outer honeycomb surface. Stresses were found to be well within the material allowable stresses. Stresses and displacements for the panel modified by the lower surface honeycomb cutout described earlier were found to be similar to the unmodified panel. Similar results were obtained for a maximum gradient thermal loading case.

\section{Sizing}

A simplified, one-dimensional computer code for sizing metallic and competing thermal protection systems for a specified location on a vehicle has been developed has been developed and is being enhanced at NASA LaRC. The program consists of a onedimensional, nonlinear, finite element model of each TPS concept which is used in an iterative manner to calculate the TPS thickness required to protect a given substructure from a specified surface heat flux history. The code also provides an option to simultaneously size TPS and cryogenic insulation for a vehicle containing cryogenic fuel. A study is in progress to compare the mass of advanced metallic TPS with competing TPS concepts with consistent assumptions over a range of parameters. Figure 6 shows a weight comparison between 8 and $12 \mathrm{lb} / \mathrm{ft}^{3}$ density AETB tiles with TUFI and RCG coating and the advanced metallic TPS concepts described in the current paper. The metallic panels fabricated and tested in the current program are calculated to be lighter than the rigid ceramic tiles with comparable resistance to rain erosion (based on $\mathrm{F}-15$ rain erosion tests). The advanced metallic TPS panels described later in this paper offer further weight savings. Operability and durability also play a critical role in TPS performance. The weight savings can easily be traded for increased durability by increasing the thickness of the outer facesheet to better resist rain erosion and impact.

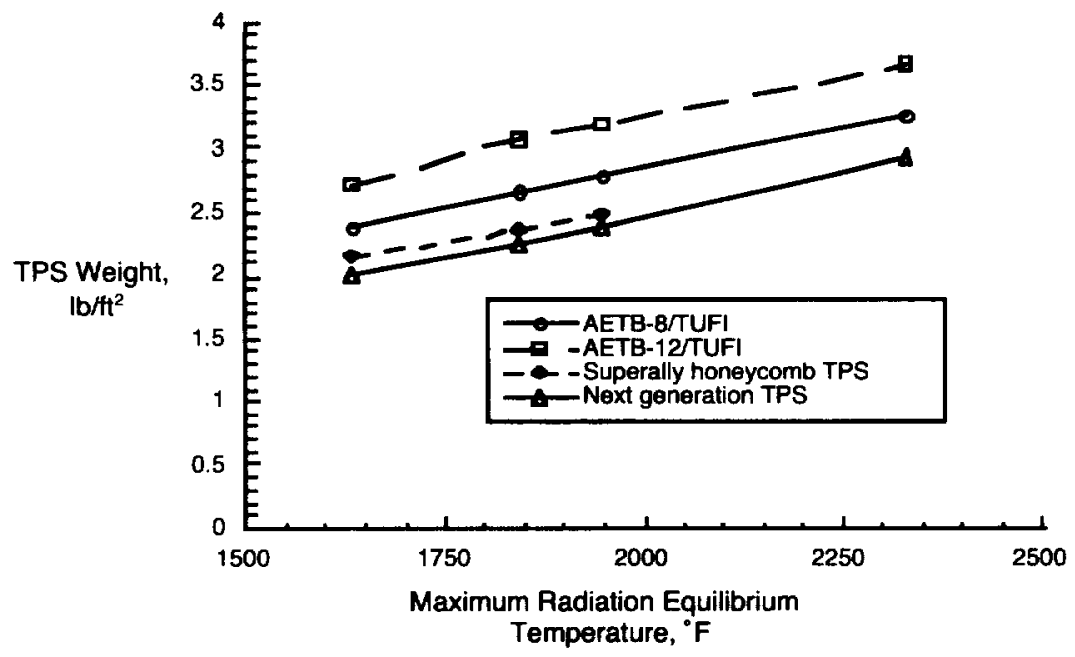

FIGURE 6. Mass Comparisons Between Metallic TPS and Advanced Rigid Ceramic Tiles. 


\section{FABRICATION}

Eight superalloy honeycomb TPS panels were fabricated by Rohr Industries. Seven of the TPS panels were fabricated to contain saffil alumina insulation compressed to a density of $3 \mathrm{lb} / \mathrm{ft}^{3}$ and the remaining panel was fabricated to contain IMI insulation. Six of the TPS panels were fabricated with the cutout of the inner titanium honeycomb sandwich described earlier. The panel containing IMI and one panel containing saffil alumina insulation were fabricated with the inner titanium honeycomb sandwich intact. Three one-foot-square Inconel 617 honeycomb sandwich panels and three one-foot square Ti 6Al-4V honeycomb sandwich panels representative of the outer surface of a metallic TPS panel were also fabricated for use in coupon tests.

The superalloy honeycomb TPS panels were fabricated using the same techniques as previously fabricated panels (Blair 1985, Anderson 1989, and Gorton 1993). The outer Inconel 617 honeycomb sandwich was fabricated by brazing 0.005 inch-thick facesheets to 0.28 inch-deep core made from 0.0015 inch-thick foil formed into $3 / 16$ inch diameter cells. The 0.003 inch-thick side walls were formed into their beaded shape with appropriate flanges to form over- or underhanging lips and brazed to the Inconel honeycomb sandwich. The fastener access tubes and covers were fabricated and brazed to the outer honeycomb sandwich. The lower honeycomb sandwich was liquid interface diffusion bonded together. Internal insulation was installed and the Inconel side walls were brazed to the titanium lower surface to complete the TPS panel.

An alternative welding fabrication process was pursued with Astech Manufacturing, Inc. Several 1-foot by 3-foot honeycomb panels were fabricated from Haynes 230, a material readily available to Astech Manufacturing. The panels consisted of 0.005 inch-thick facesheets welded to a 0.25 inch-deep core made using 0.002 inch-thick foil forming 0.25 inch-diameter cells. The core is formed by shaping individual foil ribbons so that when spot welded together they form core with the desired cell size and depth. Each core ribbon is formed with a flange on both edges to provide a surface to weld to the facesheets. The honeycomb panel is welded together in a special digitally controlled welding machine. The core ribbons are welded into the honeycomb sandwich one at a time. A ribbon is first spotwelded to an adjacent ribbon, then the ribbon is seam welded simultaneously to the upper and lower facesheets. The resulting core-facesheet joint is not as strong as a brazed joint, but has few defects and, for the same gage materials, the honeycomb sandwich is about 10 percent lighter as a result of eliminating the braze material.

\section{TESTING}

A significant testing program was undertaken to evaluate the suitability of the superalloy honeycomb TPS for application to the RLV. Internal insulations are being developed and characterized. Honeycomb sandwich coupons, simulating the outer surface of the TPS were subjected to rain erosion, low speed impact, and hypervelocity impact, with subsequent arcjet exposure. A two-panel array was subjected to simulated RLV heating and pressure entry profiles to better understand the thermal performance. A four panel array was subjected to two arcjet runs and subsequently tested in an acoustic environment.

\section{Insulation}

Several types of internal insulation are being considered for use in the metallic TPS panels. Two insulation types are shown in figure 7 , saffil alumina and IMI. Saffil alumina, manufactured by ICI Chemicals and Polymers Limited, is a fibrous insulation consisting of fine alumina fibers ( 3 micron diameter). Saffil alumina offers the potential to perform well as internal TPS insulation, however the insulation properties are not well 
characterized for TPS application. IMI, manufactured by MAN Technologies, consists of multiple layers of reflecting screens separated by fibrous insulation spacers. The foils are thin carbon/silicon carbide $(\mathrm{C} / \mathrm{SiC})$ composite layers coated by reflective layers of either gold or platinum. The reflective layers are separated by thin layers of saffil alumina or quartz fibrous insulation. A preliminary steady-state thermal test at MDA indicated that a particular IMI configuration had about half the thermal conductance as an equivalent mass of saffil alumina. MAN Technologies uses a proprietary thermal analysis code to design IMI stack-ups for a particular application. As mentioned earlier, NASA LaRC has developed a thermal analysis code to predict the thermal performance of multiple layer insulations such as IMI. However, additional test data is being developed to validate the analysis.

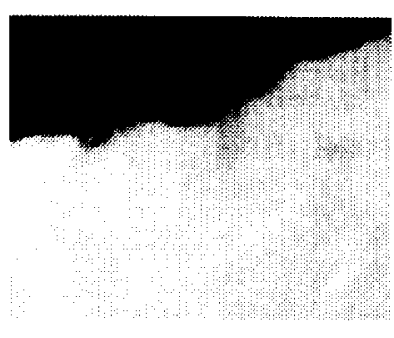

Saffil Alumina

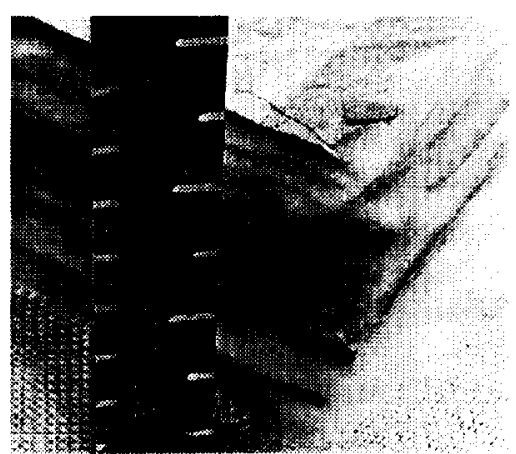

Internal Multiscreen Insulation

FIGURE 7. Internal Insulations for Metallic TPS.

NASA LaRC also sponsored a small development effort to investigate the possibility of coating saffil alumina fibers with reflective coating to reduce its thermal conductivity. Several coatings were successfully applied to saffil alumina using an inexpensive solgel process. However, a satisfactory means of evaluating the effectiveness of the coatings was not available during the coating development effort.

Another potential candidate internal insulation is a multilayer insulation being developed under a Small Business Innovative Research (SBIR) effort sponsored by NASA-Ames Research Center. Again, there is a need to characterize the thermal performance of this insulation for TPS application.

A clear need for a an experimental method of characterizing the thermal performance of insulation for TPS applications is evident from the previous discussion. Because no currently available, satisfactory testing service or facility was found, a testing apparatus (see figure 8) has been developed at NASA LaRC to characterize the thermal performance of insulations for metallic TPS. The apparatus is simple in principle. An insulation sample is sandwiched between a hot plate and a water-cooled plate. Thermocouples measure the temperature drop across the sample and heat flux gages measure the heat flux through the insulation sample. This information can be used to calculate an effective thermal conductivity of the insulation sample. With care, thermocouples may be installed within the sample to obtain the effective conductivity of different layers of the insulation sample. The one-foot-square hot plate, insulation sample and water-cooled plate are encapsulated in rigid insulation to reduce lateral heat loss. This entire assembly can be tested in air or in a vacuum chamber to control the pressure and composition of gas in the insulation sample. This apparatus has been fabricated and instrumented and is currently being checked out. 


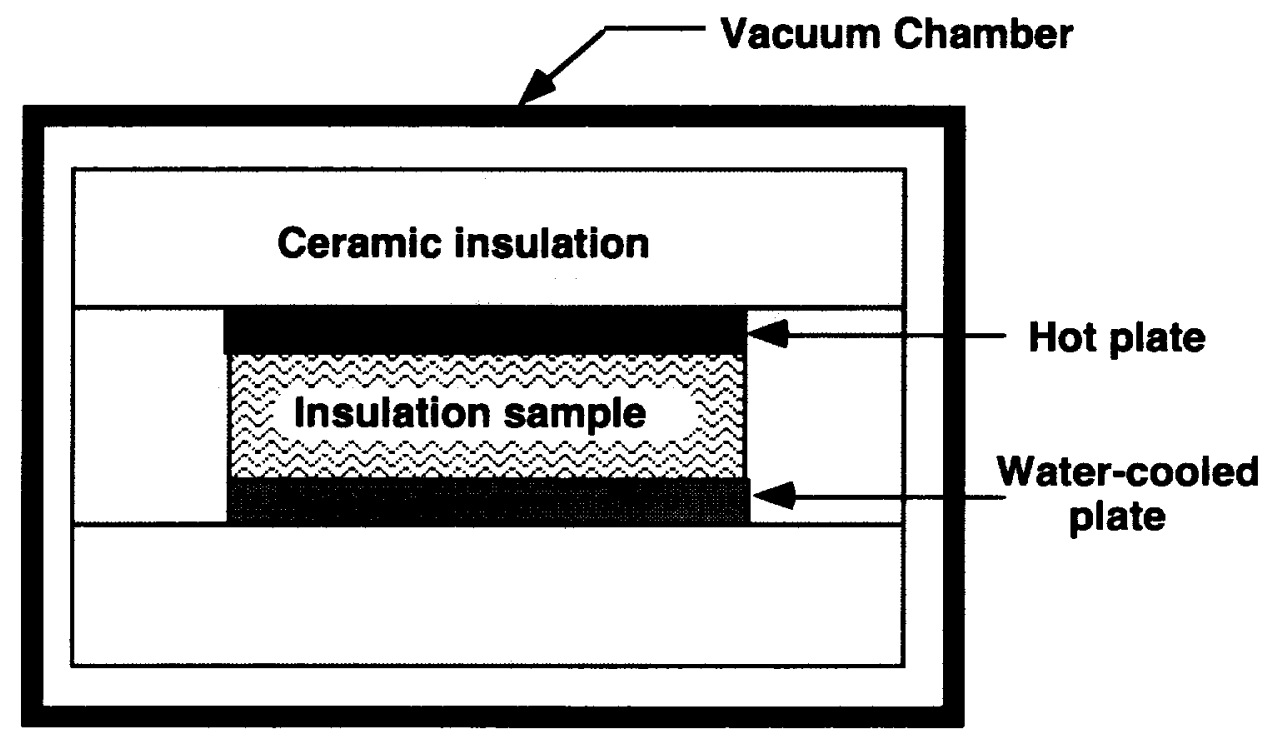

FIGURE 8: Insulation Characterization Apparatus.

\section{Honeycomb sandwich coupon tests}

For many of the durability tests, a small honeycomb sandwich coupon, representative of the outer surface of a TPS panel, was tested so that destruction of an entire TPS panel was not required. Samples were cut from the honeycomb sandwich panels described in the fabrication section, as well as from honeycomb sandwich panels with different facesheet and core geometries fabricated during previous TPS development efforts (Blair 1985, Anderson 1989).

\section{Rain Erosion}

The rain erosion resistance of the TPS is one of the key RLV operability issues. If the TPS can survive rain impact, the vehicle's economic viability and performance will be improved because it will not be as restricted by adverse weather conditions.

Two different types of rain erosion tests were performed on the honeycomb sandwich specimens. Small, 1 inch diameter, specimens were tested in the rotation arm facility at the University of Dayton. Larger, 4 inch by 6 inch and 4 inch by 4 inch specimens were flight tested on an F-15 aircraft.

Both preoxidized and unoxidized specimens were tested at a number of speeds and angles of attack in the rotating arm facility. One inch diameter specimens of both Inconel 617 and $\mathrm{Ti} 6 \mathrm{Al}-4 \mathrm{~V}$ honeycomb sandwich with 0.005 inch-thick facesheets and 0.25 inch deep core with $3 / 16$ inch diameter cells made from 0.0015 inch-thick foil were tested at $30^{\circ}, 60^{\circ}$, and $90^{\circ}$ angles of attack at speeds of 140,409 and $650 \mathrm{mph}$ for 90 and 180 seconds. The $2 \mathrm{~mm}$ diameter water drops were produced at a rate to simulate a rainfall rate of 1 inch per hour. The unoxidized Inconel 617 specimens, after exposure to rain erosion, are shown in figure 9. The specimens exhibited no significant damage at $30^{\circ}$ angle of attack or at $140 \mathrm{mph}$. At $60^{\circ}$ and $90^{\circ}$ angle of attack for velocities of 409 and $650 \mathrm{mph}$, the specimens were severely damaged with facesheet cracking. Similar results were obtained for the titanium specimens, except that the failure mode was a breaking of the facesheet to core bond rather than the facesheet cracking observed in the Inconel 
specimens. Preoxidized and unoxidized Inconel 617 specimens exhibited similar behavior, however the preoxidized titanium specimens exhibited slightly more facesheet-to-core bond failures than the unoxidized specimens. Both the preoxidized Inconel 617 and titanium specimens were subjected to arcjet testing in the Panel Test Facility (PTF) at NASA Ames following the rain erosion tests. The Inconel 617 specimens were tested at approximately $1800^{\circ} \mathrm{F}$ and the titanium specimens were tested at $1000^{\circ} \mathrm{F}$ for 13 minutes. The oxide layers on both materials changed appearance but the extent of physical damage did not appear to change. The core-to-facesheet joints in the titanium specimens, however, may have been furtherembrittled.

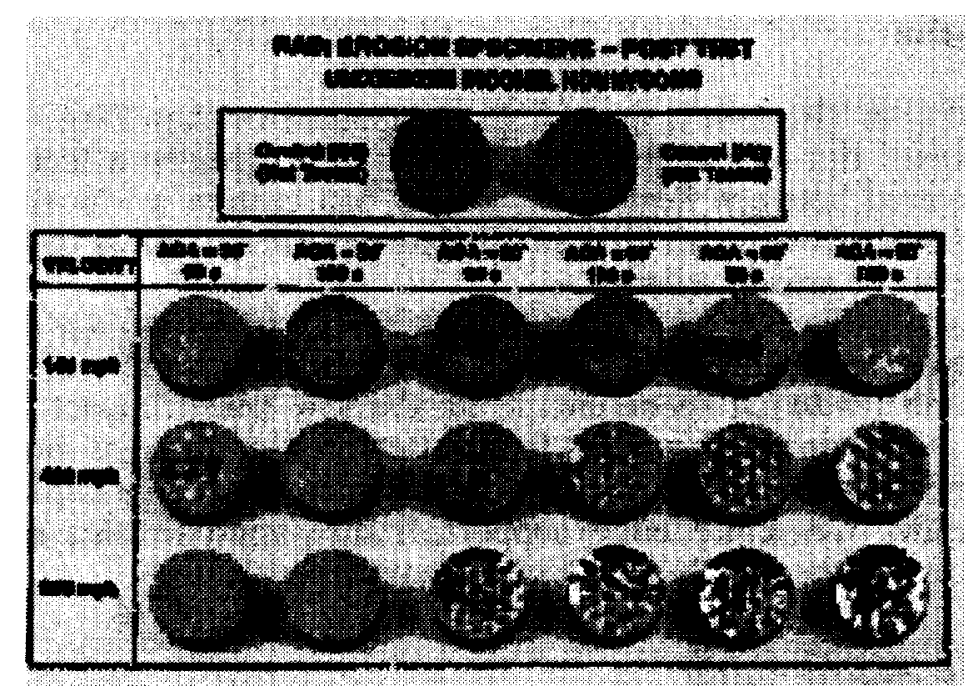

FIGURE 9. Inconel 617 Honeycomb Coupons Tested in Rotating Arm Rain Erosion Facility.

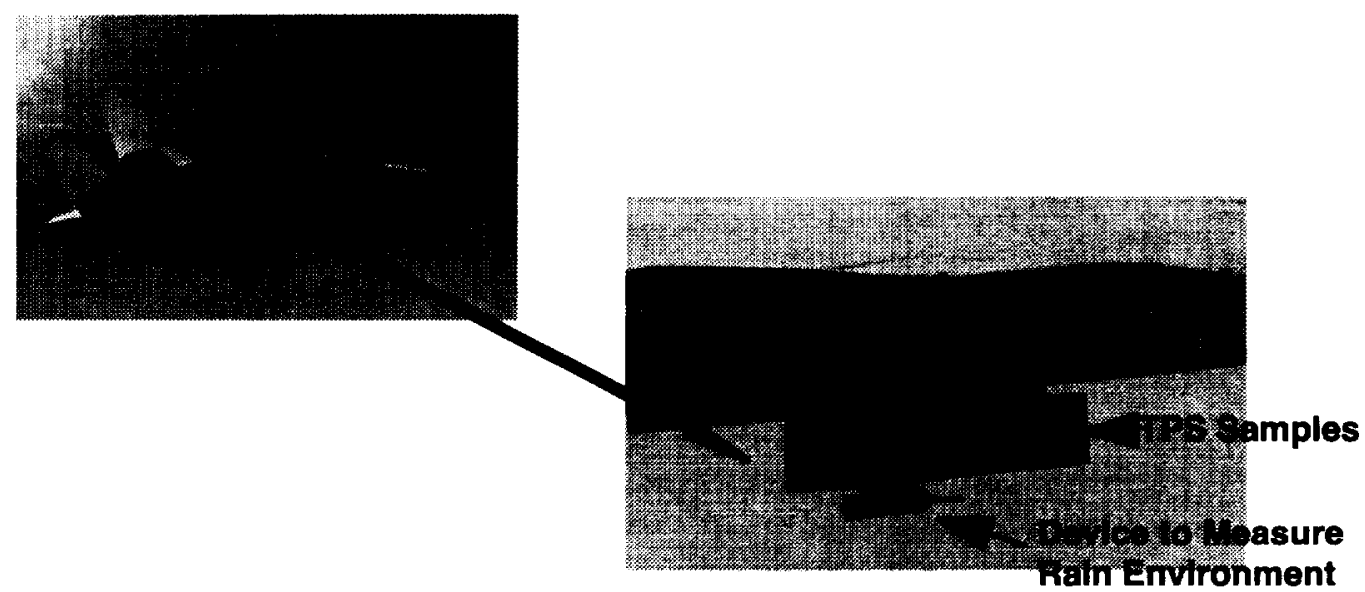

FIGURE 10. Rain Erosion Flight Tests On An F-15 Aircraft.

Rain erosion flight tests on an F-15 aircraft were conducted by Rockwell International at NASA Dryden. A special fixture was designed to suspend TPS samples beneath an F-15 aircraft as shown in figure 10 . The fixture provided for eight rows of TPS samples. Each row had a sample at $0^{\circ}, 10^{\circ}$ and $20^{\circ}$ angle of attack. Therefore eight TPS concepts could each be tested at three different angles of attack. The primary purpose of the tests was to 
evaluate the rain erosion resistance of rigid ceramic tiles and flexible blankets. However, preoxidized Inconel 617 and titanium honeycomb sandwich samples were also tested. The metallic specimens were flown at a variety of conditions from light mist to very heavy rain at speeds up to 500 knots over the course of five test flights. The $0^{\circ}$ and $10^{\circ}$ specimens were unchanged in appearance. The $20^{\circ}$ specimens had slight intracell dimpling of the facesheets, which was surprising since the rotating arm specimens had exhibited no dimpling at $30^{\circ}$ angle of attack at $650 \mathrm{mph}$. The dimpling may be due to the occasional impact with drops much larger than $2 \mathrm{~mm}$ diameter encountered in the much longer exposure times in real rainfall during the flight tests. Note that the damage that was observed was for a much more severe environment than that expected for acreage areas of the RLV.

\section{Low speed impact}

The susceptibility of TPS to low speed impact damage from handling, tool drop and low speed debris impact during launch and landing will greatly affect the amount of refurbishment required between flights. If a TPS can sustain a low speed impact with minimal or acceptable damage so that immediate refurbishment is not required, TPS maintenance time can be greatly reduced.

Low speed impact tests were performed (Karr 1996) on a variety of Inconel 617 and titanium honeycomb sandwich specimens using the low speed impact facility at NASA LaRC (fig. 11). The dropped weight facility features a dropped impactor which is instrumented to measure the impact force profile. Interchangeable impact heads provide variable impact radii. A knife edge support fixture approximates simply supported boundary conditions for the 4-inch-square impact specimens.
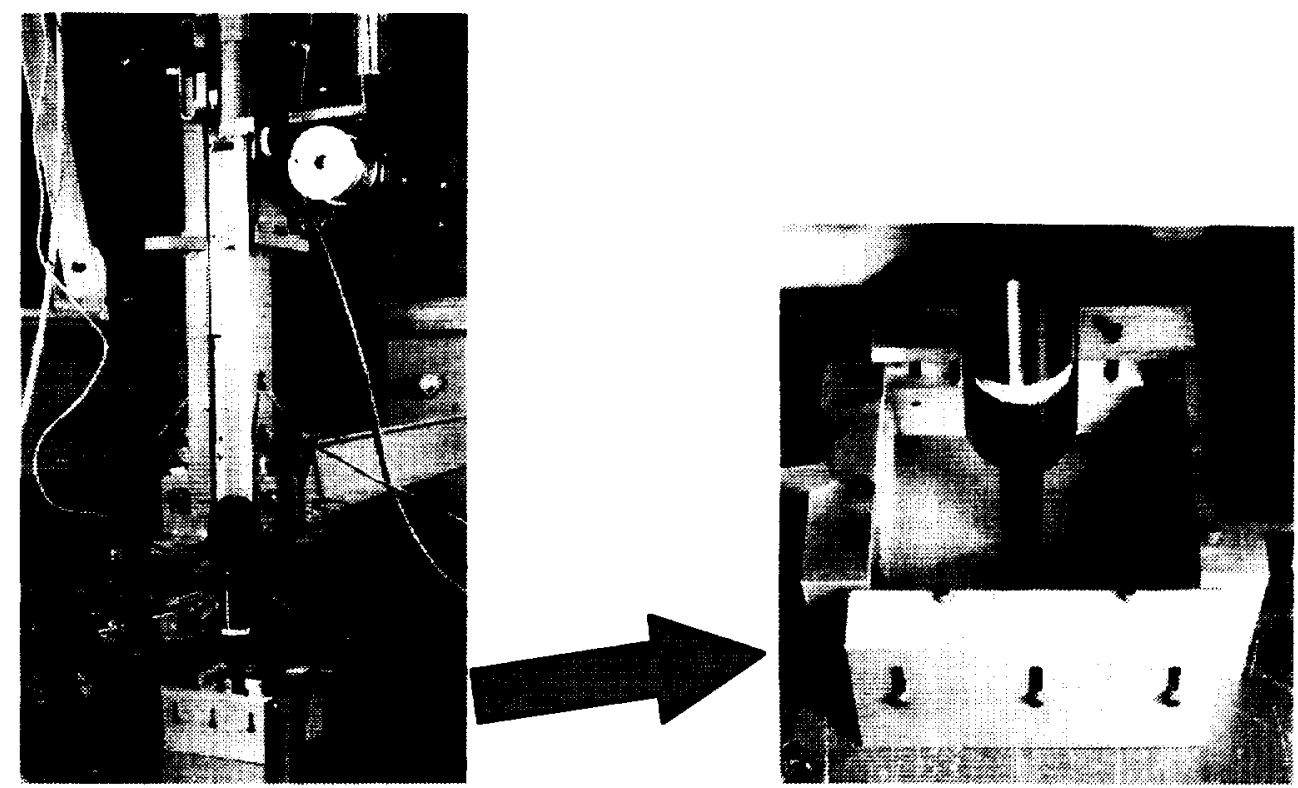

FIGURE 11. Low Speed Impact Test Apparatus.

Inconel 617 honeycomb sandwich specimens with facesheets from 0.0025 to 0.010 inches thick and titanium honeycomb sandwich specimens with facesheets form 0.003 to 0.016 inches thick were tested (Karr 1996). Impact energies ranged from 1 to $10 \mathrm{ft}$-lb and impact diameters ranged from 0.25 to 4.0 inches. The objectives of the testing were to 
characterize the material response to low speed impact and develop a method to design for low speed impact resistance. An example of the test results and characterizationmethod is illustrated in figure 12 . A specimen impacted by a 0.25 inch diameter impactor at an energy of $2 \mathrm{ft}$-lb produced the force profile shown. The peaks in the force profile correspond to the impact head encountering the two facesheets of the honeycomb sandwich. Sharp drops in the force profile near the force peaks correspond to the impactor breaking through the facesheet. The impact force profile can be integrated and manipulated to calculate the impact energy as a function of time during the impact. By determining the impact energy at the time of the facesheet cracking, a threshold value was calculated. Plotting the resultant threshold values as a function of facesheet thickness produces the chart on the lower left of figure 12 which can be used for design purposes.

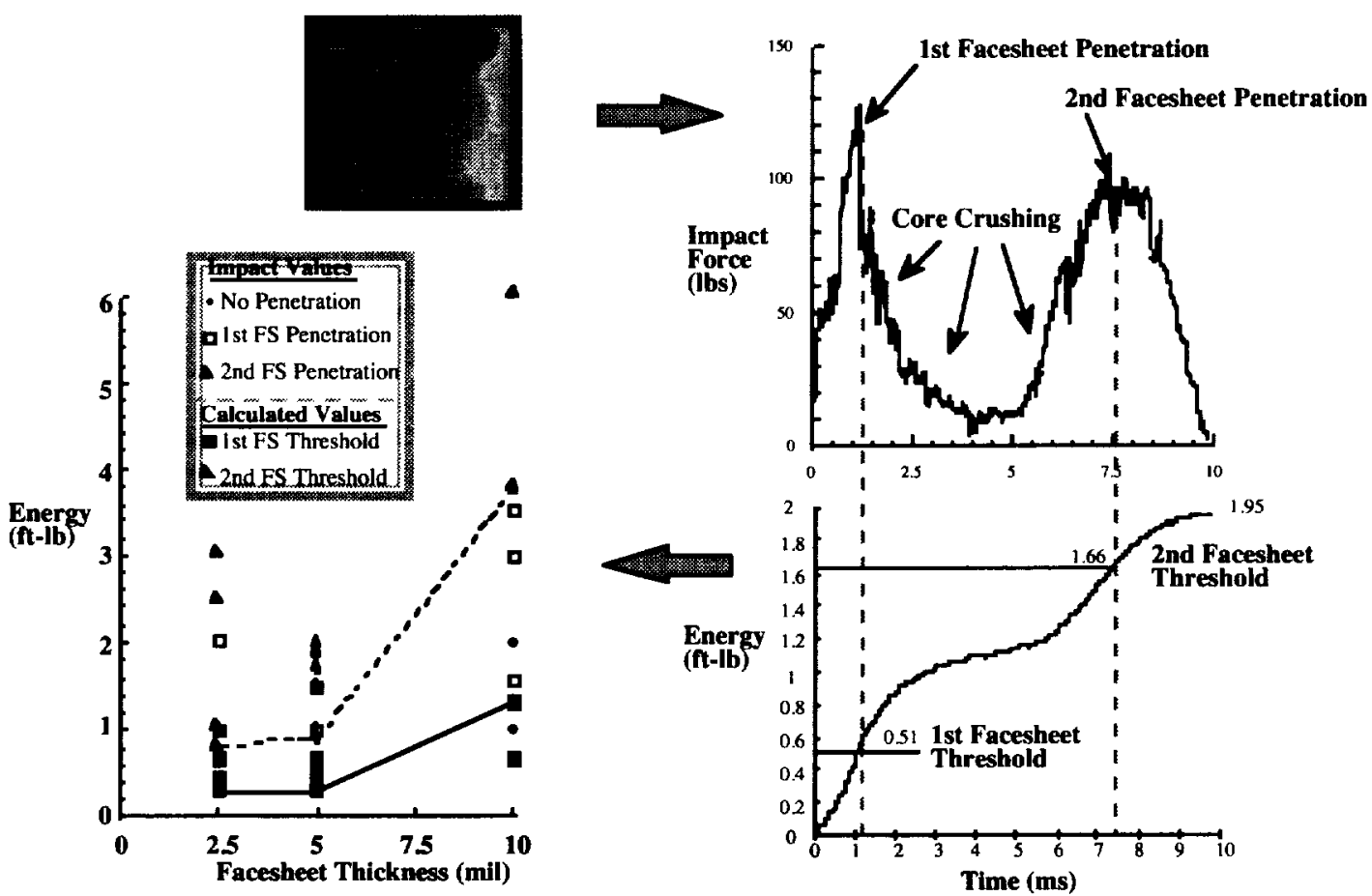

FIGURE 12. Low Speed Impact Characterization Of Inconel Honeycomb Sandwich.

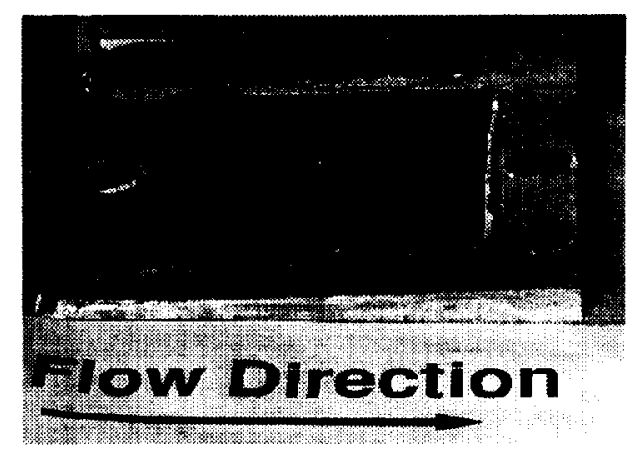

FIGURE 13. Inconel 617 Low Speed Impact Specimen After Arcjet Exposure.

Three preoxidized Inconel 617 and titanium specimens were impacted by $0.25,0.625$ and 4.0 inch-diameter impact heads and subsequently exposed to arcjet flow in the PTF at 
NASA Ames Research Center. One of the specimens is shown in figure 13. The Inconel and titanium specimens were exposed to 13 minutes of flow at $1800^{\circ} \mathrm{F}$ and $1000^{\circ} \mathrm{F}$ respectively. Some of the Inconel specimens experienced a spallation of some of the oxidation on the outer surface. The reason for this loss of oxide layer is not totally understood, but it appears to be related to a pattern of overheating on the specimen surface. The arcjet flow did not appear to enlarge the damaged area on the specimens.

\section{Hypervelocity impact}

The threat of hypervelocity impact from micrometeorites and especially man made space debris is an increasing concern for spacecraft and reusable launch vehicles. Because the TPS will cover most of the external surface of the RLV, it is important to understand how well the TPS can withstand hypervelocity impacts and how well it can protect the underlying structure from damage.

More than 30 metallic TPS specimens were tested at the light gas gun facility at NASA Marshall Space Flight Center (MSFC). A special fixture was developed to hold honeycomb sandwich coupons, internal insulation, a coupon of titanium foil or honeycomb, and substructure panel to simulate a TPS panel attached to a substructure. Aluminum spheres from 0.125 to 0.25 diameters were fired at the specimens at $7 \mathrm{~km} / \mathrm{sec}$. The baseline Inconel 617 honeycomb sandwich with 0.005 inch-thick facesheets was able to disintegrate the 0.125 inch sphere so that the 0.10 inch thick aluminum substructure was only slightly pitted. However, the 0.25 inch diameter sphere produced a large hole in the aluminum substructure after penetrating the Inconel honeycomb sandwich, internal insulation, and 0.003 inch-thick titanium back surface. Figure 14 shows typical damage to the outer honeycomb sandwich. A small hole is produced in the outer surface, but the particle begins to break up and creates a much larger hole on the inner surface of the sandwich. Several Inconel 617 and titanium panels subject to hypervelocity impacts were subsequently tested in the PTF arcjet at NASA Ames. For the other impact specimens, the arcjet flow appeared to cause some changes to the oxide layer on the outer surface, but did not enlarge the damaged area.

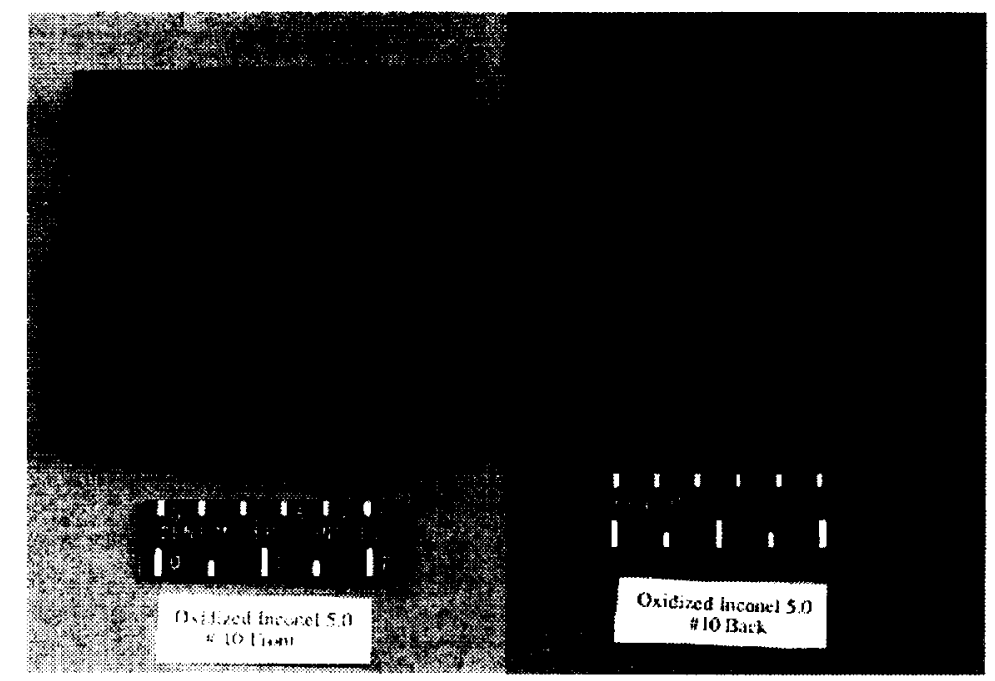

FIGURE 14. Oxidized Inconel 617 Honeycomb Sandwich Coupon After Hypervelocity Impact. 


\section{TPS panel tests}

A number of TPS panel tests were conducted to try to evaluate the performance of the metallic TPS panels to simulated RLV environments. A two panel array was tested in a thermal vacuum facility with carefully controlled thermal boundary conditions to characterize the thermal performance of the TPS panels and their thermal deformations. A four-panel array was tested in arcjet flow to determine the response to the hot gas environment. The four panel array was subsequently tested in an acoustic environment to simulate the engine acoustic loads. For the thermal tests it was desirable to preoxidize the panel before testing. This was not feasible during fabrication, because it was feared the preoxidation of the Inconel sides would significantly weaken the Inconel-to-titanium joint at the bottom of the sides. A special oven was constructed at MDA to heat the outer Inconel 617 surface to $1900^{\circ} \mathrm{F}$ for one hour while allowing the titanium lower surface to remain below $1000^{\circ} \mathrm{F}$.

\section{Thermal vacuum TPS panel tests}

The purpose of the two-panel array thermal vacuum tests is to characterize the thermal response of the TPS panels to a simulated RLV thermal and pressure history. The results will be used to validate the thermal analysis of the TPS panels.

A one by two foot quartz lamp heater was constructed and installed in an existing 5-foot diameter vacuum chamber. A surrogate specimen was used to develop the control techniques required to simulate RLV heating and pressure profiles. An array of two identical panels is shown in figure 15. One of the panels was instrumented with more than 30 thermocouples and three displacement transducers. The array was subjected to five simulated entry cycles with highly repeatable results. The uninstrumented TPS panel was then replaced with an instrumented TPS panel containing IMI. The tests of this second array are in progress.

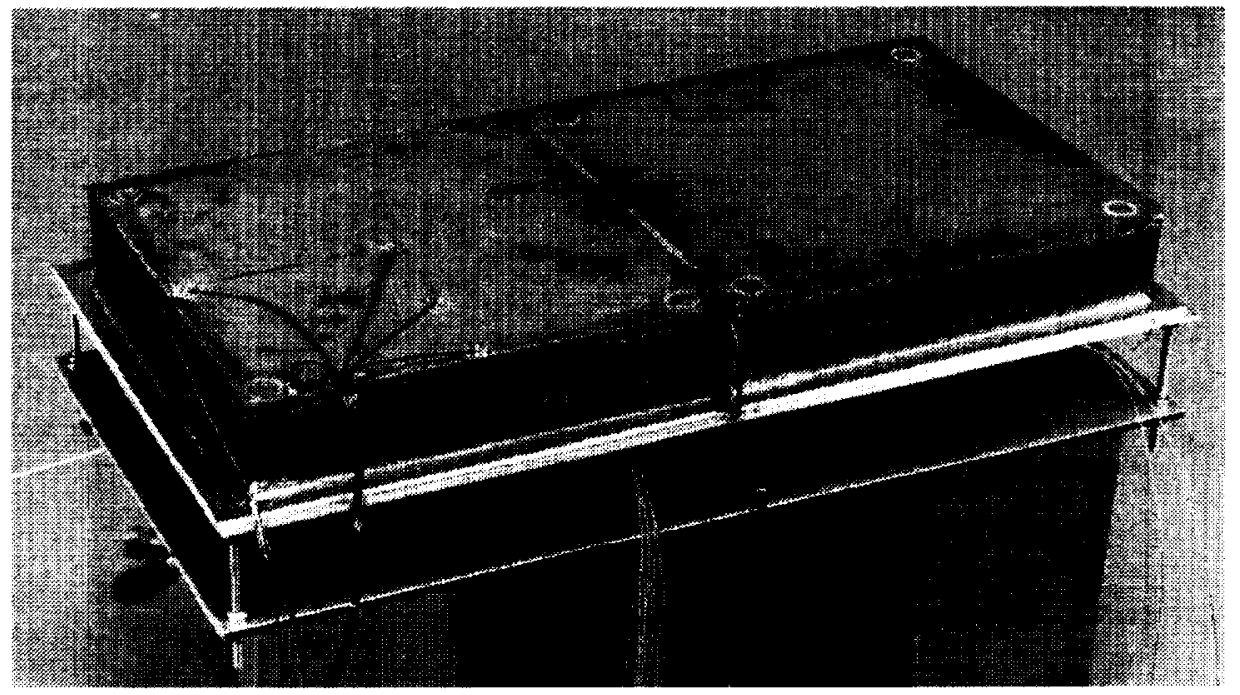

FIGURE 15. Instrumented Two-Panel Array Before Thermal Vacuum Testing. 


\section{Arcjet TPS panel tests}

One of the objectives of the arcjet tests of the four panel array was to determine whether significant hot gas flow would occur in the gaps between panels. Careful attention was paid to the boundary conditions to avoid any unrealistic subsurface hot gas flow. The gaps between the TPS panels and the model holder were stuffed with fibrous insulation and 0.030 inch-thick Inconel flanges were used to simulate the overhanging lips of upstream TPS panels. The gap between the substructure and the model holder was sealed with RTV adhesive.

The four panel array shown in figure 16 was tested in the IHF arcjet at NASA Ames. The four TPS panels were mounted to a representative composite fluted core structural panel using bonded on threaded studs. Thermocouples were located at several locations down the sides of the panels in the gaps and on the substructure. A infrared thermal camera was used to observe the temperature distribution on the surface of the array. Unfortunately there was a problem recording the infrared data and much of it was lost. The preoxidized four panel array is shown before arcjet testing in figure 16. The array was tested in two different arcjet runs. The first run was a check out run lasting less than five minutes. The panels reached the desired maximum temperature of nearly $1850^{\circ} \mathrm{F}$ and information was obtained to help determine how long to make the second run. The second run lasted 11 minutes with a maximum surface temperature of approximately $1860^{\circ} \mathrm{F}$. The composite substructure reached a peak temperature of just under the $350^{\circ} \mathrm{F}$ allowable temperature. Visual observations and infrared camera images during the test did not indicate a surface heating variation which would be expected from the anticipated thermal bowing of the panels. This was surprising because earlier tests of similar panels in NASA LaRC's 8 Foot High Temperature tunnel had resulted in heating variations associated with thermal bowing of the panels. The TPS panels survived the two arcjet run with no sign of any damage as shown in figure 17 . The surface oxidation appeared to transition from a greenish chromium oxide toward a dark gray nickel oxide.

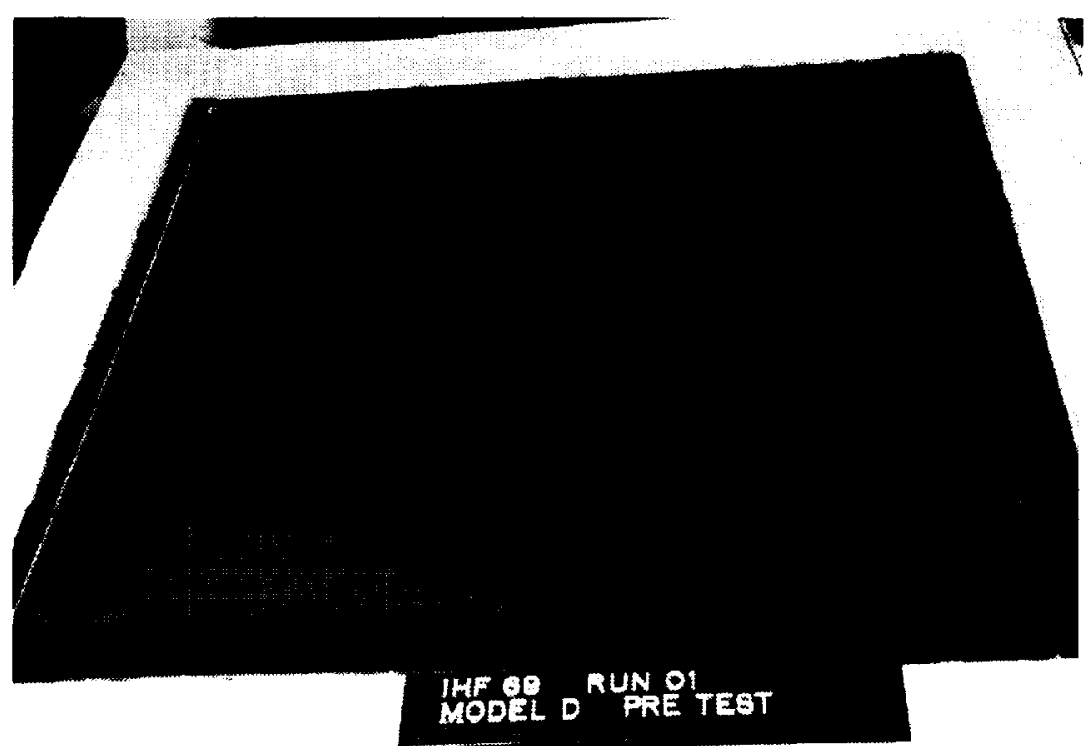

FIGURE 16. Metallic TPS Four-Panel Array Before Arcjet Testing. 


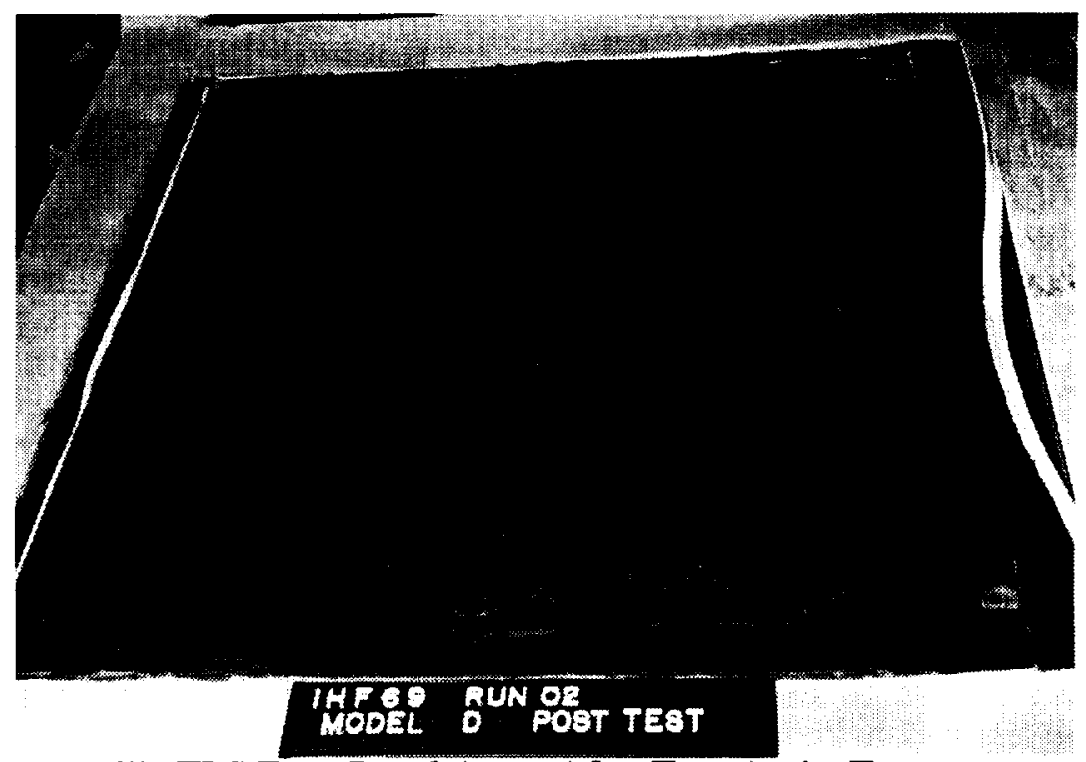

FIGURE 17. Metallic TPS Four-Panel Array After Two Arcjet Tests.

Some of the temperatures measured during the second arcjet run are shown in figure 18 . Temperature histories down the side of the TPS panels are shown for several locations along both the gap parallel to the flow as well as the gap perpendicular to the flow. If there was significant hot gas flow in the gap between panels the thermocouples in the gap parallel to the flow should read significantly hotter than the thermocouples in the gap perpendicular to the flow. There is no such pattern in the measured temperatures and therefore no evidence of hot gas flow in the gap between panels.

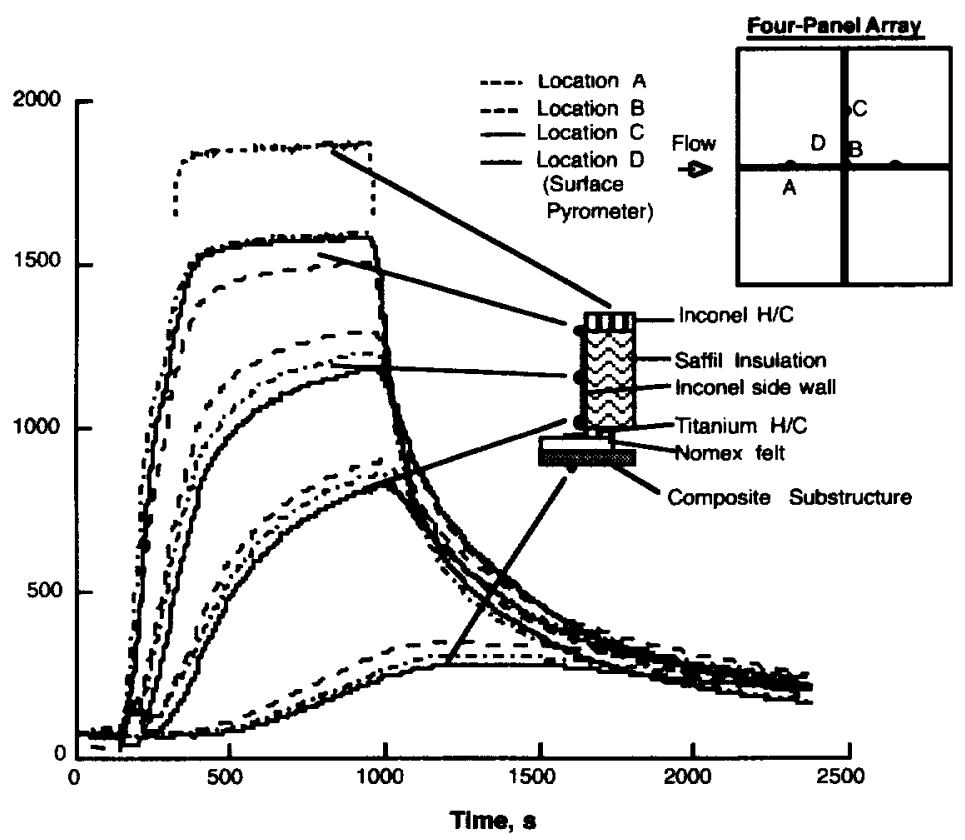

FIGURE 18. Temperature Histories Measure on Four Panel Array During Arcjet Test. 


\section{Acoustic TPS panel tests}

The four panel array which had been tested in the arcjet was scheduled for subsequent acoustic tests. However, several modifications to the array were required. The composite substructure used in the arcjet tests was slightly undersized so that the edges of TPS panels overhung the edge of the substructure. For the arcjet tests the overhang did not matter, however for the acoustic tests unsupported edges may have led to premature failure similar that encountered in previous testing (Gorton 1993). The TPS panels were, therefore transferred to a larger substructure. In the removal process, one of the fastener access tubes on a panel broke loose from the panel because the fastener access cover was stuck. One of the panels was replaced by the TPS panel containing IMI for the acoustic tests. The panels were again attached to the structure by bonded on threaded studs.

The resulting four panel array was sent to Wright Laboratory for acoustic testing simulating an RLV environment. After some initial check out tests, one of the panels did not appear to be tightly fastened down. The fasteners were tightened and the tests initiated. After less than a minute of testing, one of the panels experienced significant rigid body motion and the test was halted. It was discovered that two of the bonded on studs had become disbonded. At that point the tests were discontinued until the bonded on studs could be reevaluated. Once the bonded-on stud problem is resolved, the four panel array will be retested.

\section{CONCEPT IMPROVEMENT}

Many ideas for improving metallic TPS have become apparent during this technology development program. Figure 19 illustrates a next generation design for prepackaged superalloy honeycomb TPS that takes advantage of some significant improvements. The outer honeycomb sandwich and sides can be made from a higher temperature alloy material such as PM 2000. PM 2000 is an iron-based, oxide dispersion strengthened (ODS) alloy that forms a protective alumina oxide coating that exhibits good static oxidation resistance up to $2400^{\circ} \mathrm{F}$. Tests are in progress to evaluate the material's performance in a hot gas, arcjet, environment. If this alloy is found to be suitable, it can significantly extend the range of application for uncoated metallic TPS. It is anticipated that the ongoing effort to characterize advanced insulations will identify improved insulations that will reduce the mass of metallic TPS. Also, improved brazing and welding fabrication techniques may offer the potential for weight and cost savings.

Several configuration improvements offer the potential to further decrease mass, decrease fabrication cost and increase operability. The underhanging lip can be eliminated to allow a single panel to be removed without requiring the removal of adjacent panels. The lower surface can be lightened and simplified by making a simple titanium frame with a foil sheet attached to it rather than the honeycomb panel with a cutout. The most innovative and effective modification, however, is the use of quick release fasteners. The fastener uses a simple wire clip that snaps into a groove of a stud attached to the structure. The fastener is released by sliding a special "scissors-like" tool into the gap between panels and squeezing the ends of the wire together. A thin slot or notch in the gap cover allows the tool to be inserted into the gap. When the panels heat up and expand the gaps begin to close and the slots slide over the adjacent panels. This fastener concept has no loose parts, is quick and simple to operate, and eliminates the costly and troublesome fastener access tubes and covers. Detailed design work remains to be done but the concept appears feasible. Also, making the panel larger (18 inches instead of 12 inches square) will result in significant cost and weight savings. Additional effort is warranted to identify and address the factors that limit panel size. 


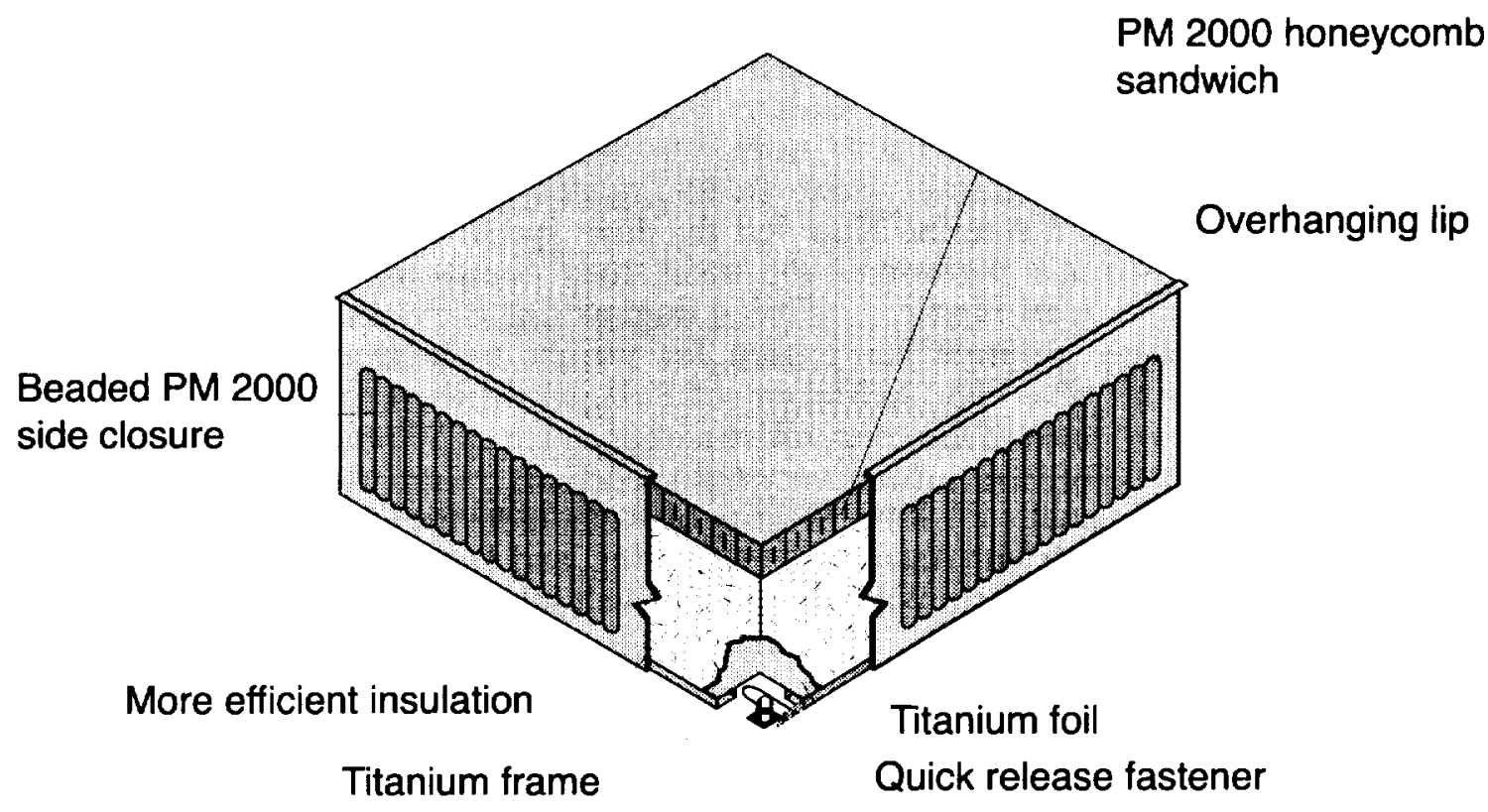

FIGURE 19. Next Generation Prepackaged Metallic TPS Panel.

\section{SUMMARY}

A significant amount of technology development for metallic TPS has been accomplished in the first phase of the RLV program. Building on metallic TPS concepts developed as an alternative to the ceramic TPS on the Shuttle orbiter, incrementally improved metallic TPS panels were design, fabricated and tested for application to the RLV. Numerous coupon tests were completed to characterize the durability of the outer surface of the metallic TPS.

Internal insulations for metallic TPS are being developed and characterized. An experimental apparatus has been designed and fabricated and is being checked out. A number of advanced insulations are being investigated. Analytical tools to predict the complex heat transfer behavior of fibrous and multilayer insulations have been developed and are being validated.

Metallic TPS panels have been fabricated and tested to characterize their behavior in simulated RLV environments. Foil gage honeycomb sandwich coupons have been used to characterize the response of metallic TPS to rain erosion, low speed impact and hypervelocity impact. Thermal vacuum tests of two panel arrays are being used to characterize the thermal response of metallic TPS panels to simulated RLV entry heating and pressure profiles. A four panel array survived two arcjet runs with no damage and no evidence of hot gas flow in the gaps between panels. Acoustic tests of a four panel array were prematurely halted because two bonded on studs that hold the panels to the substructure came loose. A next generation metallic TPS concept is identified which is more operable, has lower mass, and has lower cost than the current concept and can be designed for the required durability. The experience obtained with metallic TPS in the current study indicates that it is an attractive, viable candidate for application to the Reusable Launch Vehicle. 


\section{Acknowledgments}

The results presented in this paper represent the contributions of many people from both NASA and industry. At NASA LaRC: Kamran Daryabeigi has developed the IMI analysis code and led the thermal/vacuum and insulation characterization testing, Dana Gould performed the 3-D thermal analysis, Brian Beaton helped conceive and define the quick release fastener concept, Katherine Karr led the low speed and hypervelocity impact testing, and Dutch Myers is performing the trade study comparing the mass of metallic TPS to other concepts. Carl Martin, Lockheed Engineering Services developed the onedimensional TPS sizing program being used for weight trade studies and performed structural analysis of metallic TPS. At McDonnell Douglas Aerospace: Neil Campbell lead the MDA effort through most of the cooperative agreement, Ray Schmidt did a good job of getting all the arcjet testing done under a very tight schedule, Frank Myers coordinated the fabrication of the TPS panel with John Meaney of Rohr Industries and the fabrication of welded metallic honeycomb with Astech Manufacturing, and Don Wieland led the acoustic testing of the 4-panel array. Eric Watts from Rockwell International led the rain erosion testing on the F-15.

\section{References}

Anderson, J., LeHolm, R. B., Meaney, J. E. and Rosenthal, H. A. (1989) "Development of Reusable Metallic Thermal Protection System Panels for Entry Vehicles," NASA CR 181783, August 1989.

Blair, W., Meaney, J. E., and Rosenthal, H. A. (1984) "Re-Design and Fabrication of Titanium Multi-Wall Thermal Protection System (TPS) Test Panels," NASA CR 172247, January 1984.

Blair, W., Meaney, J. E., and Rosenthal, H. A. (1985) "Fabrication of Prepackaged Superalloy Honeycomb Thermal Protection System (TPS) Panels," NASA CR 3755, October 1985.

Bohon, H. L., Shideler, J. L., and Rummler, D. R. (1977) "Radiative Metallic Thermal Protection Systems: A Status Report," in Journal of Spacecraft and Rockets, Vol. 12, No. 10. Pp. 626-631, October 1977.

Cook, S. (1996) "The X-33 Advanced Technology Demonstrator," AIAA-96-1195, Presented at the AIAA Dynamics Specialists Conference, Salt Lake City, UT, April 1819, 1996.

David, Leonard (1996) "X-33 Flight Test Vehicle to Use Metallic Panels," in Space News, Vol. 7, No. 37, September 23-29, 1996.

Green, Michael, (1996) "Thermal Protection Systems, Ceramic," in Satisfaction of OMB/OSTP RLV Phase I Criteria. Presented to the Technology Commercialization Advisory Committee -- Space Transportation Panel, NASA Headquarters, March 7-8, 1996.

Gorton, M. P., Shideler, J. L., and Web, G. L., (1993) "Static and Aerothermal Tests of a Superalloy Honeycomb Prepackaged Thermal Protection System," NASA TP 3257, March 1993. 
Jackson, L. R. and Dixon, S. C. (1980) "A Design Assessment of Multiwall, Metallic Stand-off, and RSI Reusable Thermal Protection Systems Including Space Shuttle Application," NASA TM 81780, 96 pages, April 1980.

Karr, Katherine L. (1996) "Experimental Low Speed Impact Damage Threshold of a Metallic Thermal Protection System," Master's thesis. School of Engineering and Applied Science, George Washington University, August 1996.

Muhlratzer, A., Handrick, K., and Weber, K. H., (1990) "Hermes Thermal Protection System, Internal Multilayer Insulation (IMI)," presented at IAF, International Astronautical Congress, 41 st, Dresden, Federal Republic of Germany, 7 p, Oct. 6-12, 1990.

Shideler, J. L., Kelly, H. N., Avery, D. E., Blosser, M. L., and Adelman, H. M. (1982) "Multiwall TPS - An Emerging Concept," in Journal of Spacecraft and Rockets, Vol. 19, No. 4, July-August 1982, Pp. 358-365.

Veneri, R., De Filippes, P., and Williamson, C., (1989) "Development of Hermes IMI High Temperature Flexible Insulation," presented at the 19th Intersociety Conference on Environmental Systems, San Diego, CA, July, 1989.

Whetstone, W. D., (1985) "EISI-EAL Engineering Analysis Language Reference Manual, System Level 312," Engineering Information Services, Inc., San Jose, CA, Aug. 1985. 


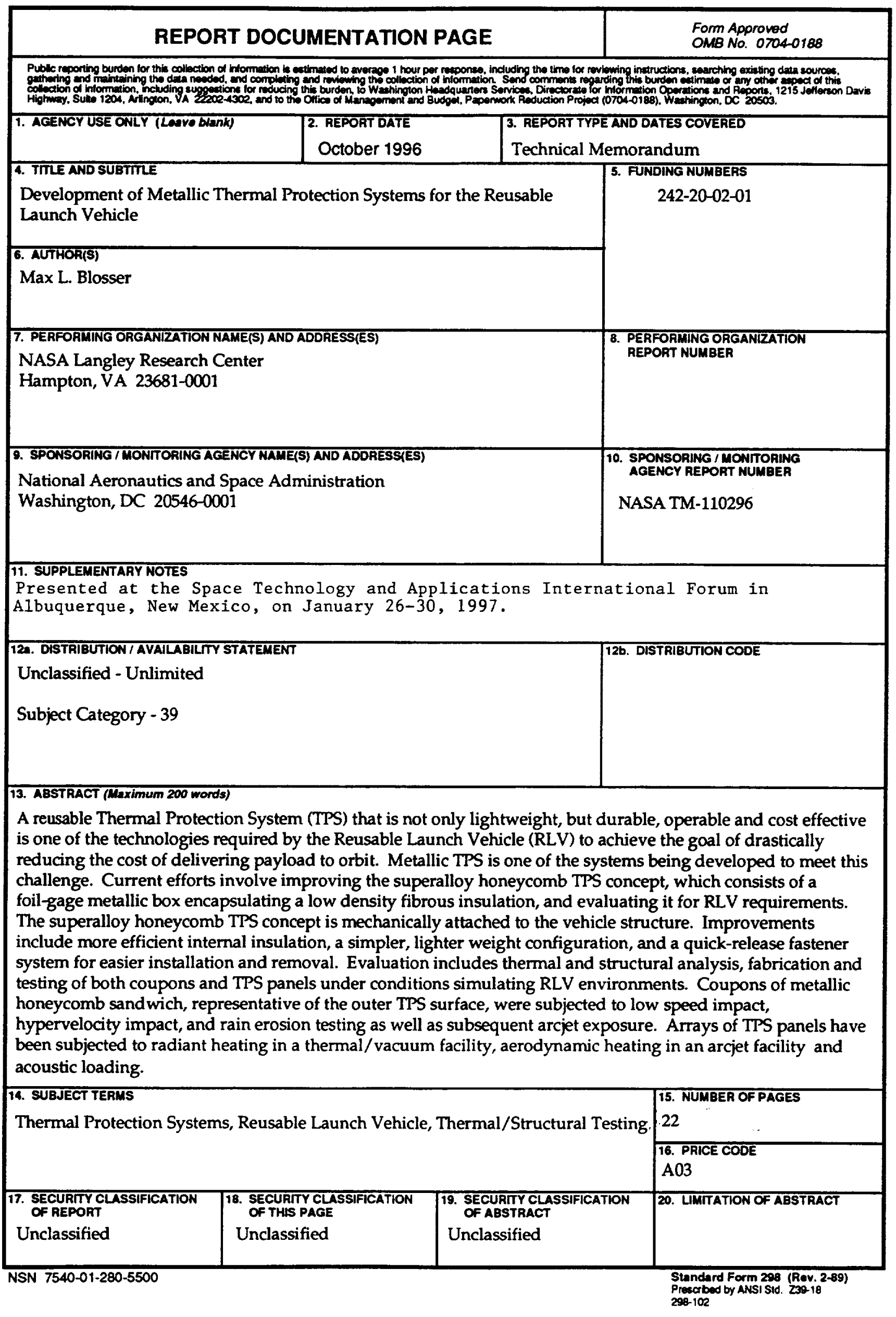

